\title{
Relationship between PI3K/mTOR/RhoA pathway- regulated cytoskeletal rearrangements and phagocytic capacity of macrophages
}

\author{
H.R. Bao (i) ${ }^{*}$, J.L. Chen (i)*, F. Li (i), X.L. Zeng(ii), and X.J. Liu (i) \\ Department of Gerontal Respiratory Medicine, The First Hospital of Lanzhou University, Lanzhou, Gansu, China
}

\begin{abstract}
The objective of this study was to investigate the relationship between $\mathrm{PI} / 3 \mathrm{~K} / \mathrm{mTOR} / \mathrm{RhoA}$ signaling regulated cytoskeletal rearrangements and phagocytic capacity of macrophages. RAW264.7 macrophages were divided into four groups; blank control, negative control, PI3K-RNAi, and mTOR-RNAi. The cytoskeletal changes in the macrophages were observed. Furthermore, the phagocytic capacity of macrophages against Escherichia coli is reported as mean fluorescence intensity (MFI) and percent phagocytosis. Transfection yielded 82.1 and $81.5 \%$ gene-silencing efficiencies against PI3K and mTOR, respectively. The PI3K-RNAi group had lower mRNA and protein expression levels of PI3K, mTOR, and RhoA than the blank and negative control groups $(P<0.01)$. The mTOR-RNAi group had lower mRNA and protein levels of mTOR and RhoA than the blank and the negative control groups $(P<0.01)$. Macrophages in the PI3K-RNAi group exhibited stiff and inflexible morphology with short, disorganized filopodia and reduced number of stress fibers. Macrophages in the mTOR-RNAi group displayed pronounced cellular deformations with long, dense filopodia and an increased number of stress fibers. The PI3KRNAi group exhibited lower MFI and percent phagocytosis than blank and negative control groups, whereas the mTOR-RNAi group displayed higher MFI and percent phagocytosis than the blank and negative controls $(P<0.01)$. Before and after transfection, the mRNA and protein levels of PI3K were both positively correlated with mTOR and RhoA $(P<0.05)$, but the mRNA and protein levels of mTOR were negatively correlated with those of RhoA $(P<0.05)$. Changes in the phagocytic capacity of macrophages were associated with cytoskeletal rearrangements and were regulated by the $\mathrm{PI} 3 \mathrm{~K} / \mathrm{mTOR} / \mathrm{RhoA}$ signaling pathway.
\end{abstract}

Key words: Phagocytosis; Cytoskeleton; PI3K; mTOR; RNA interference

\section{Introduction}

Chronic obstructive pulmonary disease (COPD) poses a serious threat to human health and is showing a gradual rise in incidence and mortality rates (1). It is expected to rank third in the world in terms of incidence and mortality rates by 2020, imposing huge economic burdens (2). COPD is a complex and heterogeneous disease at the clinical and cellular levels, with airflow obstruction and a progressive decline in lung function, including smallairway obstructions and emphysema (3). Recent studies found that a decline in the phagocytic capacity of alveolar macrophages (AM) reduced their bacterial eradication rate and thus, led to frequent acute exacerbations in patients with COPD and asthma $(4,5)$. AM are capable of immune surveillance and pathogen eradication and serve as the first line of defense in the human immune system (6). Therefore, it is important to investigate the exact mechanism underlying the weakened phagocytic capacity of $\mathrm{AM}$, in order to understand the acute exacerbations of COPD.

It is well known that the process of phagocytosis is accompanied by dramatic changes in actin cytoskeletal rearrangements and phosphoinositide 3-kinases (PI3K)related signaling pathways $(7,8)$. It is also well known that PI3Ks are a family of lipid kinase proteins that regulate the growth, proliferation, and cytoskeletal rearrangements of cells (9). Mammalian target of rapamycin (mTOR) is a serine/threonine protein kinase present downstream to $\mathrm{PI} 3 \mathrm{~K}$ that regulates cell growth, migration, metabolism, and cytoskeletal rearrangements $(10,11)$. Ras homolog gene family member A (Rho A) is a small-molecular weight protein present downstream to mTOR. It affects the phagocytic functions of cells by regulating the assembly of

Correspondence: X.J. Liu <liuxiaoju835@126.com>

*These authors are co-first authors.

Received August 10, 2019 | Accepted March 26, 2020 
actin and myosin filaments as well as cell adhesion, but it needs to be phosphorylated into $p$-RhoA to exercise its functions (12). Freeman et al. (13) found that PI3K-mTOR signaling pathway regulates the phagocytic capacity of macrophages, while mTOR modulates cytoskeletal rearrangements by regulating its downstream protein $\mathrm{RhoA}$ so that it can be activated via phosphorylation into $p-R h o A$ (14). However, the relationship of $\mathrm{PI} 3 \mathrm{~K} / \mathrm{mTOR} / \mathrm{RhoA}$ signaling pathway with cytoskeletal rearrangements and phagocytic capacity of macrophages is rarely reported. Therefore, we inhibited the PI3K/mTOR/RhoA signaling pathway via RNA interference (RNAi) to elucidate its relationship with cytoskeletal rearrangements and phagocytic capacity of macrophages.

\section{Material and Methods}

\section{Cell culture and experimental groups}

RAW264.7 cells (The Cell Bank of Type Culture Collection of Chinese Academy of Sciences, China) were sub-cultured in Dulbecco's modified Eagle medium (DMEM, Hyclone Laboratories, Inc., USA) containing $10 \%$ fetal bovine serum (FBS, Clark Bioscience, USA) in $5 \% \mathrm{CO}_{2}$ at $37^{\circ} \mathrm{C}$, and were divided into four experimental groups as follows: blank control, negative control, PI3K-RNAi, and mTOR-RNAi. The cells in the negative control group were transfected with shRNA (random sequence), while the cells in PI3K-RNAi and mTOR-RNAi groups were transfected with PI3K-shRNA and mTOR-shRNA (Guangzhou Saiye Biotechnology Co., Ltd., China), respectively. The cells in the blank group were not transfected with any vector. All experiments were repeated three times.

\section{Lipofection of RAW264.7 cells}

Plasmids were isolated in strict accordance with the endotoxin-free plasmid extraction kit (Tiangen Biotech Co., Ltd., China). RAW264.7 cells grown to logarithmic phase were inoculated at $2 \times 10^{5}$ cells/well into a 6 -well plate containing OPTI-MEM medium (Gibco, Invitrogen Corp., USA) and transfected with Lipofectamine ${ }^{\mathrm{TM}} 2000$ (Invitrogen Corp., USA) /plasmid DNA complex at a ratio of 2.5:1. After being incubation in $5 \% \mathrm{CO}_{2}$ at $37^{\circ} \mathrm{C}$ for $6 \mathrm{~h}$, the OPTI-MEM medium (Gibco, Invitrogen Corp.) was replaced with DMEM complete medium and the cells were further incubated for $72 \mathrm{~h}$. Transfection efficiency was determined by western blot analysis examining the shRNA with the highest transfection efficiency for PI3K and mTOR genes, respectively.

\section{Construction of lentiviral vectors}

PI3K-shRNA, mTOR-shRNA, and negative-control shRNA (Guangzhou Saiye Biotechnology Co., Ltd.), which had the highest transfection efficiencies, were subjected to lentiviral packaging and titration (Guangzhou Saiye Biotechnology Co., Ltd.). All vectors had titers greater than $1 \times 10^{8} \mathrm{TU} / \mathrm{mL}$. Cells grown to logarithmic phase were inoculated into a 6 -well plate at $1 \times 10^{5}$ cells $/$ well. Each of the wells was supplemented with $6 \mu \mathrm{g} / \mathrm{mL}$ of polybrene (Guangzhou Saiye Biotechnology Co., Ltd.), and the cells were transfected at a multiplicity of infection (MOI: the lentivirus-to-cell ratio) of 100 . After being transfected for $24 \mathrm{~h}$ in $5 \% \mathrm{CO}_{2}$ at $37^{\circ} \mathrm{C}$, the virus-containing medium was replaced with DMEM complete medium and the cells were further incubated for $72 \mathrm{~h}$ before observing the expression of enhanced green fluorescent protein (EGFP) under an inverted fluorescence microscope (CKX41, Olympus Co., Japan). Furthermore, the cells were harvested and divided into two portions: one portion was used for the determination of gene-silencing efficiency against PI3K and mTOR, while the other portion was sub-cultured.

\section{Determination of mRNA levels by real-time quantitative PCR}

The total RNA samples extracted from cells of the different groups were subjected to cDNA synthesis using the PrimeScript ${ }^{\mathrm{TM}}$ RT reagent Kit (TaKaRa Bio., Inc., Japan), followed by the determination of mRNA levels of PI3K, mTOR, and RhoA according to manufacturer's instructions. Their primers were as follows: PI3K: upstream primer: 5'CCCATGGGACAACATTCCAA3', downstream primer: 5'CATGGCGACAAGCTCGGTA3'; mTOR: upstream primer: 5'CCCGGACAAGGACAGACTCCTA3', downstream primer: 5'GGTTTCACCAAACCGTCTCCA3; RhoA: upstream primer: 5'CAGCAAGGACCAGTTCCCA GA3', downstream primer: 5'AGCTGTGTCCCATAAAGC CAACTC3'. PCR amplification was carried out under the following conditions: pre-denaturation at $95^{\circ} \mathrm{C}$ for $30 \mathrm{~s}$, followed by 40 cycles of denaturation at $95^{\circ} \mathrm{C}$ for $5 \mathrm{~s}$ and annealing and extension at $60^{\circ} \mathrm{C}$ for $34 \mathrm{~s}$. The relative expression level of each target gene was calculated using the $2^{-\triangle \triangle \mathrm{Ct}}$ method.

\section{Western blot assay of protein expressions}

The cell suspension was centrifuged at $2000 \mathrm{~g}$ for $5 \mathrm{~min}$ at $4^{\circ} \mathrm{C}$, and the supernatant was discarded. Ice-cold PBS was added to the cell pellet, and washed and centrifuged the cells at $2000 \mathrm{~g}$ for $5-7 \mathrm{~min}$ at $4^{\circ} \mathrm{C}$, and the supernatant was discarded, and repeated three times. Icecold lysis buffer (Beijing Solarbio Science \& Technology Co., Ltd., China) was added to the cell pellet. The contents were agitated in microfuge tubes for $30 \mathrm{~min}$ at $4^{\circ} \mathrm{C}$. The tubes were centrifuged at $16,000 \mathrm{~g}$ for $20 \mathrm{~min}$ at $4^{\circ} \mathrm{C}$. The supernatant was collected in fresh tubes and placed on ice, and was used for the measurement of protein concentrations via bicinchoninic acid (BCA) assay. The protein samples were then denatured in a water bath for $5 \mathrm{~min}$ and $20 \mu \mathrm{L}$ each were loaded for separation by sodium dodecyl sulfate-polyacrylamide gel electrophoresis (SDS-PAGE, Beijing Solarbio Science \& Technology Co., Ltd.). The separated proteins were transferred by wet transfer method onto a PVDF membrane, which was then 
blocked with 5\% skim milk (Beijing Solarbio Science \& Technology Co., Ltd.) for $30 \mathrm{~min}$. The membrane was subsequently incubated overnight at $4^{\circ} \mathrm{C}$ (in the refrigerator) with the following primary antibodies: rabbit antiPI3K p85 $\alpha$ antibody (Abcam plc., England) (1:1500), rabbit anti-mTOR antibody (ImmunoWay Biotechnology Co., USA) (1:500), mouse anti-RhoA antibody and $p$ RhoA antibody (Abcam plc.) (1:500), and mouse anti$\beta$-actin antibody (GeneTex, Inc., USA) (1:1500) (1:2500). The membrane was then incubated at room temperature for one hour with goat anti-rabbit IgG (ImmunoWay Biotechnology Co.) (1:5000) and goat anti-mouse IgG (ImmunoWay Biotechnology Co.) (1:5000). The membrane was then exposed to the film after being incubated with enhanced chemiluminescence (ECL) substrate (Millipore, Merck KGaA, Germany). ImageJ (https://imagej.net) was used for quantification of gray intensity. The gray value of each protein band was determined by calculating the relative expression levels of each target protein, which was defined as the gray-value ratio of the target protein to the internal reference protein.

\section{Observation of cytoskeletons}

The cells in different groups were inoculated onto coverslips in a 24-well plate and incubated in the dark at $37^{\circ} \mathrm{C}$ for $6 \mathrm{~h}$ with $300 \mu \mathrm{L} /$ well of fluorescein isothiocyanate (FITC)-labeled $E$. coli (final concentration: $4 \mathrm{mg} / \mathrm{mL}$ ) (Invitrogen, Corp.). Each well was then supplemented with $100 \mu \mathrm{L}$ of $4 \%$ trypan blue (Invitrogen Corp.) to quench the extracellular fluorescence of FITC-labeled $E$. coli for one minute. After washing with phosphate-buffered saline (PBS, Beijing Solarbio Science \& Technology Co., Ltd.) thrice, the supernatant was discarded, while the remaining cells were fixed with $4 \%$ paraformaldehyde (Beijing Solarbio Science \& Technology Co., Ltd.) for $30 \mathrm{~min}$ and washed 3 times with PBS prior to being stained with 200 $\mu \mathrm{L} /$ well of rhodamine-labeled phalloidin (Cytoskeleton, Inc. USA) at room temperature for one hour. The cells were then washed thrice with PBS and mounted for subsequent observation and imaging under the confocal laser scanning microscope (Carl Zeiss AG, Germany).

\section{Determination of the phagocytic capacity against FITC-labeled $E$. coli}

The plates containing $1 \times 10^{5}$ cells/well were incubated in the dark for $6 \mathrm{~h}$ with FITC-labeled $E$. coli suspension (final concentration: $0.04 \mathrm{mg} / \mathrm{mL}$ ). Each well was then supplemented with $4 \%$ trypan blue to quench the extracellular fluorescence of FITC-labeled E. coli. The cells were then harvested via centrifugation $(16,000 \mathrm{~g}$ for $20 \mathrm{~min}$ at $4^{\circ} \mathrm{C}$ ) for determining the mean fluorescence intensity (MFI) and percentage of phagocytic cells positive for FITC-labeled E. coli (percent phagocytosis) using the Mx3000p Flow Cytometer (Becton Dickinson Co., USA). Higher MFI and percent phagocytosis indicate greater phagocytic capacities.

\section{Statistical analysis}

All data were analyzed using the software SPSS ver. 22.0 (IBM, USA). The measurement data are reported as means $\pm S D$. The pairwise comparison between groups was carried out using one-way analysis of variance (ANOVA) and LSD $t$-test. Correlation was tested via Pearson's linear correlation analysis. $\mathrm{P}<0.05$ indicated $\mathrm{a}$ statistically significant difference.

\section{Results}

Transfection and gene-silencing efficiencies of PI3KRNAi and mTOR-RNAi

After $72 \mathrm{~h}$ of transfection, EGFP could be observed on transfected cells under the inverted fluorescence microscope with transfection efficiencies $>80 \%$ (Figure 1) and gene-silencing efficiencies of $82.1 \pm 2.1$ and $81.5 \pm 2.3 \%$ for PI3K-RNAi and mTOR-RNAi, respectively. A significant decline in the protein levels of PI3K and mTOR indicated successful silencing of the target genes.

mRNA and protein expressions of PI3K, mTOR, and RhoA, as well as protein expression of $p-R h o A$

The mRNA and protein expression levels of PI3K, mTOR, and RhoA, as well as the phosphorylation levels of $p-R h o A$ protein in the cells from the PI3K-RNAi group were lower than those in the cells from the blank and negative control groups $(P<0.01)$. Both mRNA and protein expression levels of mTOR in the cells from the mTOR-RNAi group were lower than those in the cells from the blank control and negative control groups $(P<0.01)$, while the mRNA and protein expression levels of RhoA, as well as the phosphorylation level of $p$-RhoA protein were higher than those in the blank and negative control groups $(P<0.01)$ (Table 1 and Figure 2).

\section{Cytoskeletal changes in different groups}

The cells from the PI3K-RNAi group had a stiff and inflexible morphology with short, disorganized filopodia and a relatively smaller number of stress fibers than the cells in the blank group. The cells from mTOR-RNAi group displayed even more pronounced cellular deformation with long, slender, and dense filopodia, as well as a significantly greater number of stress fibers than the cells in the blank control group. Cells from both the blank and negative control groups showed relatively prominent cellular deformations with longer filopodia and a greater number of stress fibers (Figure 3 ).

\section{Phagocytic capacity against FITC-labeled E. coli}

The cells from PI3K-RNAi group showed lower MFI and lower phagocytosis than the cells from the blank and negative control groups $(P<0.01)$, whereas the cells from mTOR-RNAi group had significantly higher MFI and higher phagocytosis than the cells from the blank and negative control groups $(P<0.01)$ (Table 2$)$. 

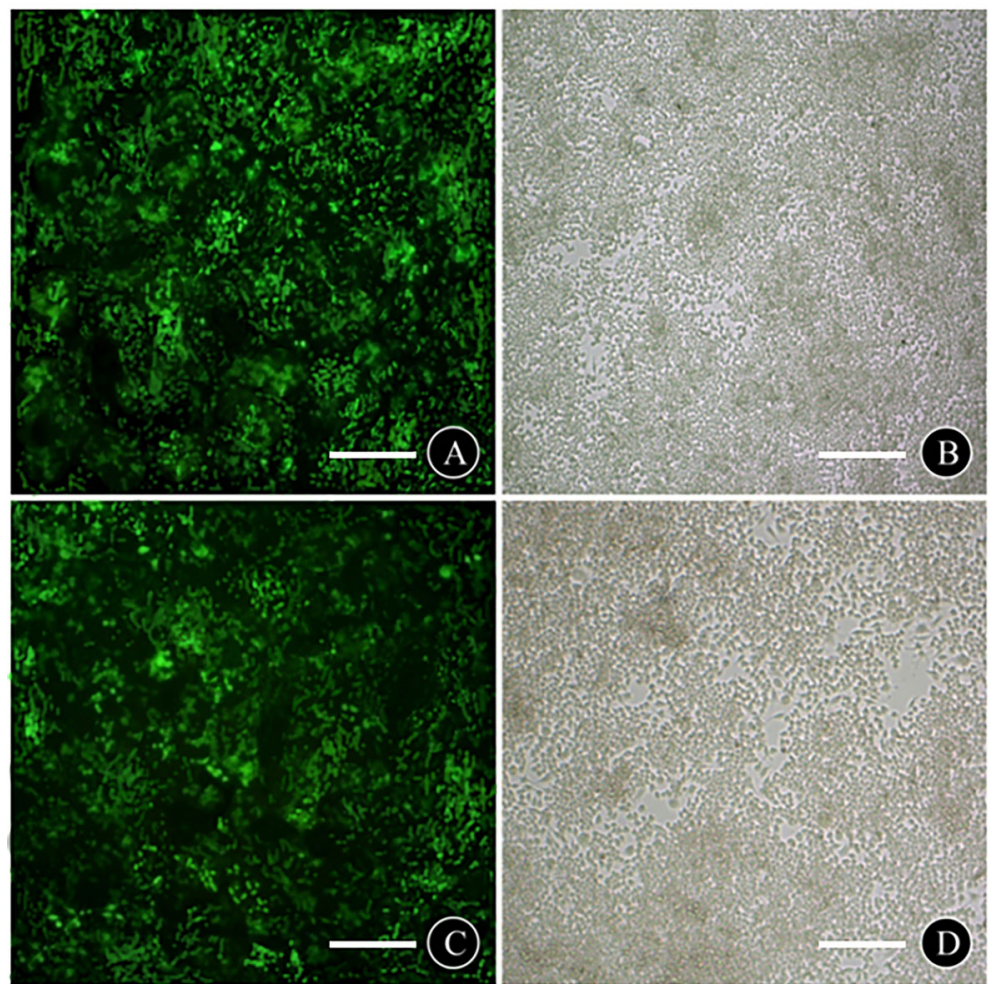

Figure 1. Transfection efficiency of cells in PI3K-RNAi and mTOR-RNAi groups after $72 \mathrm{~h}$ transfection. A, PI3K-RNAi fluorography; B, PI3K-RNAi white light graph; C, mTOR-RNAi fluorography; D, mTOR-RNAi white light graph. Scale bar, $100 \mu \mathrm{m}$.

Table 1. mRNA relative expression levels of PI3K, mTOR, and RhoA in each group (mean $\pm \mathrm{SD}$ ).

\begin{tabular}{llll}
\hline Group & \multicolumn{1}{c}{ PI3K } & \multicolumn{1}{c}{ mTOR } & \multicolumn{1}{c}{ RhoA } \\
\hline Blank control & $1.00 \pm 0.0$ & $1.00 \pm 0.00$ & $1.00 \pm 0.00$ \\
Negative control & $0.98 \pm 0.05$ & $1.01 \pm 0.11$ & $0.99 \pm 0.13$ \\
PI3K-RNAi & $0.29 \pm 0.07^{\text {aa }}$ & $0.54 \pm 0.13^{\text {aa }}$ & $0.59 \pm 0.06^{\text {aa }}$ \\
mTOR-RNAi & $1.02 \pm 0.07^{\text {bb }}$ & $0.30 \pm 0.08^{\text {aabb }}$ & $1.40 \pm 0.21^{\text {aabb }}$ \\
\hline
\end{tabular}

${ }^{\text {aa }} \mathrm{P}<0.01$ compared with the blank and negative control groups; ${ }^{\text {bb }} \mathrm{P}<0.01$ compared with the PI3K-RNAi group (ANOVA and LSD $t$-test).

\section{Correlation analysis}

Before and after transfection, the mRNA and protein expression levels of $\mathrm{PI} 3 \mathrm{~K}$ were positively correlated with that of mTOR $(P<0.05)$; the mRNA and protein expression levels of PI3K were positively correlated with that of RhoA and $p-R h o A(P<0.05)$; the mRNA and protein expression levels of $\mathrm{mTOR}$ were negatively correlated with that of RhoA and p-RhoA $(P<0.05)$ (Table 3). The mRNA and protein expression levels of PI3K and RhoA, as well as the expression level of $p-R h o A$ protein were positively correlated with MFI and percent phagocytosis $(\mathrm{P}<0.05)$; whereas mRNA and protein expression levels of $\mathrm{mTOR}$ were negatively correlated with $\mathrm{MFI}$ and percent phagocytosis $(\mathrm{P}<0.05)$ (Table 4$)$.

\section{Discussion}

The surface receptors on AM recognize pathogens and bind to ligands to activate relevant signaling pathways, such as PI3K and RhoA, which modulate cytoskeletal rearrangements to engulf exogenous particles (8). In this study, it was shown that the PI3K-mTOR-RhoA signaling pathway inhibited cytoskeletal rearrangement by affecting macrophage phagocytosis. After recognition by 

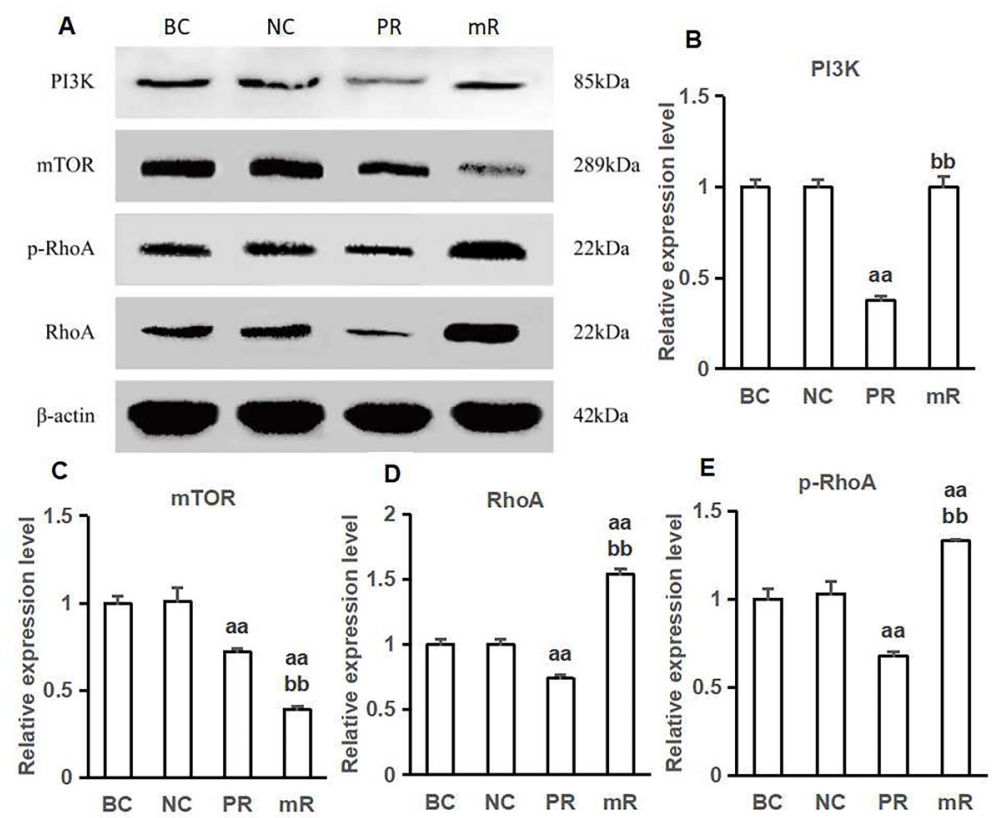

Figure 2. Expression of $\mathrm{PI} 3 \mathrm{~K}, \mathrm{mTOR}$, RhoA, and $\mathrm{p}-\mathrm{RhoA}$ proteins in each group. A, Western blot test for the expression of $\mathrm{PI} 3 \mathrm{~K}$, $\mathrm{mTOR}$, RhoA, and p-RhoA proteins. B-E, Expression levels of $\mathrm{PI3K}, \mathrm{mTOR}, \mathrm{RhOA}$, and $\mathrm{p}-\mathrm{RhoA}$ proteins in each group respectively. ${ }^{\text {aa }} \mathrm{P}<0.01$, compared with the blank control group $(\mathrm{BC})$ and the negative control group $(\mathrm{NC})$; ${ }^{\text {bb }} \mathrm{P}<0.01$, compared with the PI3K-RNAi group (PR) (ANOVA and LSD $t$-test). mR: mTOR-RNAi group.
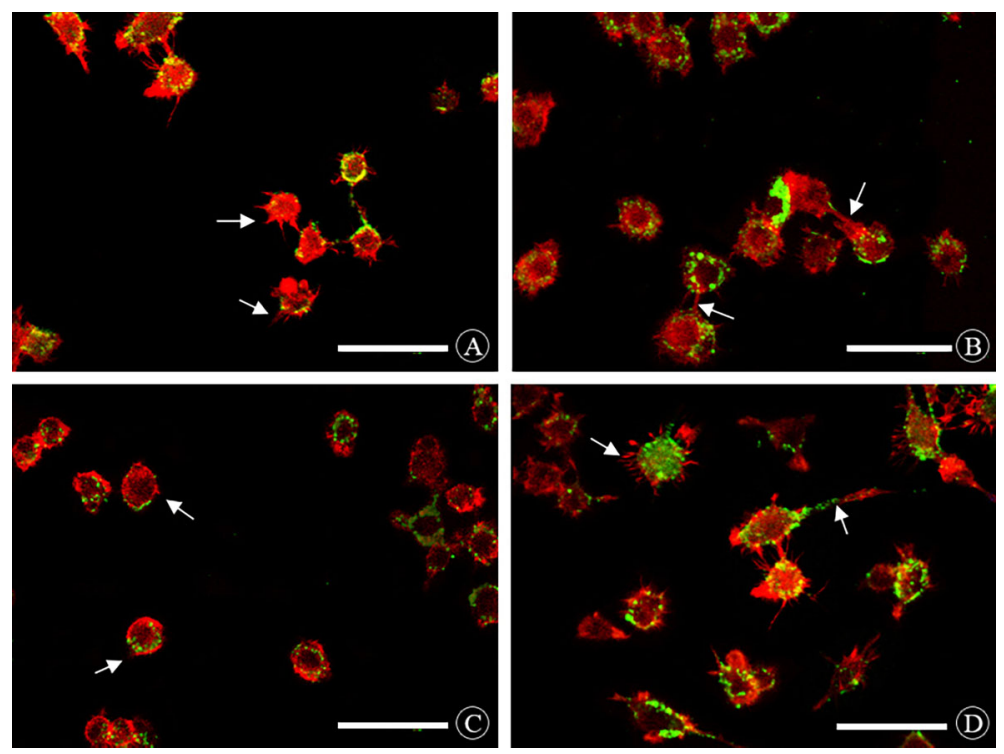

Figure 3. Cytoskeleton morphology of each group under laser confocal microscope ( $\times 400$, scale bar, $15 \mu \mathrm{m})$. A, Blank group: protruding long filamentous pseudopodium, cell deformation was obvious. B, Negative control group: protruding long filamentous pseudopod, cell deformation was obvious. C, PI3K-RNAi group: short protruding pseudopod, cell deformation was poor. D, mTOR-RNAi group: longer and denser protruding pseudopod, cell deformation was more obvious. Red fluorescence: rhodamine labeled phalloidin; Green fluorescence: FITC-E.coli. White arrow: pseudopodia. 
Table 2. Phagocytic capacity against FITC-labeled E. coli in each group (mean $\pm \mathrm{SD}$ ).

\begin{tabular}{lcc}
\hline Group & MFI & Phagocytosis (\%) \\
\hline Blank control & $11733.0 \pm 935.0$ & $79.97 \pm 1.07$ \\
Negative control & $10983.0 \pm 954.0$ & $79.60 \pm 1.17$ \\
PI3K-RNAi & $7435.0 \pm 705.0^{\text {aabb }}$ & $70.73 \pm 2.66^{\text {aabb }}$ \\
mTOR-RNAi & $18583.0 \pm 1090.0^{\text {aabb }}$ & $87.72 \pm 1.58^{\text {aabb }}$ \\
\hline
\end{tabular}

${ }^{\text {aa }} \mathrm{P}<0.01$ compared with the blank group, ${ }^{\text {bb }} \mathrm{P}<0.01$ compared with the negative control (ANOVA and LSD $t$-test). MFI: mean fluorescence intensity.

Table 3. Analysis of the correlation between PI3K, mTOR, and RhoA mRNA and proteins in each group ( $r$ value).

\begin{tabular}{|c|c|c|c|c|c|}
\hline \multirow[t]{2}{*}{ Group } & \multicolumn{2}{|c|}{ RhoA } & \multirow[t]{2}{*}{ p-RhoA protein } & \multicolumn{2}{|c|}{ mTOR } \\
\hline & mRNA & Protein & & mRNA & Protein \\
\hline \multicolumn{6}{|c|}{ Blank control } \\
\hline \multicolumn{6}{|c|}{ PI3K } \\
\hline mRNA & $0.88^{*}$ & $0.93^{* *}$ & $0.96^{* *}$ & $0.94^{* *}$ & $0.98^{* *}$ \\
\hline protein & $0.83^{*}$ & $0.97^{*}$ & $0.97^{* *}$ & $0.83^{*}$ & $0.93^{* *}$ \\
\hline \multicolumn{6}{|l|}{ mTOR } \\
\hline mRNA & $-0.86^{*}$ & $-0.96^{\star *}$ & $-0.94^{\star *}$ & - & - \\
\hline protein & $-0.94^{\star *}$ & $-0.97^{\star *}$ & $-0.99^{\star \star}$ & - & - \\
\hline \multicolumn{6}{|c|}{ Negative control } \\
\hline \multicolumn{6}{|l|}{$\mathrm{PI} 3 \mathrm{~K}$} \\
\hline mRNA & $0.90^{*}$ & $0.91^{*}$ & $0.86^{*}$ & $0.91^{\star *}$ & $0.85^{*}$ \\
\hline protein & $0.84^{*}$ & $0.97^{* *}$ & $0.88^{*}$ & $0.91^{*}$ & $0.99^{* *}$ \\
\hline \multicolumn{6}{|l|}{ mTOR } \\
\hline mRNA & $-0.95^{\star *}$ & $-0.92^{\star *}$ & $-0.91^{*}$ & - & - \\
\hline protein & $-0.91^{*}$ & $-0.85^{\star}$ & $-0.83^{*}$ & - & - \\
\hline \multicolumn{6}{|c|}{ PI3K-RNAi } \\
\hline \multicolumn{6}{|l|}{$\mathrm{PI} 3 \mathrm{~K}$} \\
\hline mRNA & $0.97^{* *}$ & $0.97^{* *}$ & $0.92^{*}$ & $0.99^{\star *}$ & $0.96^{* *}$ \\
\hline protein & $0.91^{*}$ & $0.94^{* *}$ & $0.99^{* *}$ & $0.96^{\star *}$ & $0.97^{* *}$ \\
\hline \multicolumn{6}{|l|}{ mTOR } \\
\hline mRNA & $-0.91^{*}$ & $-0.88^{*}$ & $-0.97^{\star *}$ & - & - \\
\hline protein & $-0.93^{\star *}$ & $-0.94^{\star *}$ & $-0.98^{\star \star}$ & - & - \\
\hline \multicolumn{6}{|c|}{ mTOR-RNAi } \\
\hline \multicolumn{6}{|l|}{ PI3K } \\
\hline mRNA & $0.96^{\star *}$ & $0.83^{*}$ & $0.93^{* *}$ & $0.92^{* *}$ & $0.93^{* *}$ \\
\hline protein & $0.91^{*}$ & $0.99^{* *}$ & $0.92^{* *}$ & $0.86^{*}$ & $0.92^{* *}$ \\
\hline \multicolumn{6}{|l|}{ mTOR } \\
\hline mRNA & $-0.92^{*}$ & $-0.94^{\star *}$ & $-0.92^{*}$ & - & - \\
\hline protein & $-0.95^{\star *}$ & $-0.83^{*}$ & $-0.96^{*}$ & - & - \\
\hline
\end{tabular}

${ }^{*} \mathrm{P}<0.05,{ }^{* *} \mathrm{P}<0.01$ (Pearson's linear correlation analysis).

pathogen recognition receptors (PRRs), PI3K-Akt initiates a series of phosphorylation cascades and activates mTOR, which subsequently affects cytoskeletal rearrangements by regulating the activity of RhoA; whereby mTORC2 promotes the activation of RhoA and enhances the cytoskeletal rearrangements; whereas mTORC1 reduces the activity of RhoA and inhibits the cytoskeletal rearrangements (14-16).

In this study, the expressions of PI3K and mTOR were silenced by RNAi to explore their specific roles in $\mathrm{PI} 3 \mathrm{~K} / \mathrm{mTOR} / \mathrm{RhoA}$ signaling pathway, in order to study the effects of this pathway on the phagocytic capacity of 
Table 4. Analysis of the correlation between mRNA and protein expression levels of PI3K, mTOR, RhoA, p-RhoA protein, and mean fluorescence intensity (MFI) and percent phagocytosis ( $r$ value).

\begin{tabular}{|c|c|c|c|c|c|c|c|}
\hline \multirow[t]{2}{*}{ Index/Group } & \multicolumn{2}{|c|}{ PI3K } & \multicolumn{2}{|c|}{ mTOR } & \multicolumn{2}{|c|}{ RhoA } & \multirow[t]{2}{*}{ p-RhoA protein } \\
\hline & mRNA & Protein & mRNA & Protein & mRNA & Protein & \\
\hline \multicolumn{8}{|l|}{ MFI } \\
\hline Blank control & $0.92^{*}$ & $0.93^{\star \star}$ & $-0.83^{*}$ & $-0.91^{\star}$ & $0.95^{\star *}$ & $0.84^{*}$ & $0.86^{*}$ \\
\hline Negative control & $0.93^{* *}$ & $0.92^{\star *}$ & $-0.92^{*}$ & $-0.91^{*}$ & $0.89^{*}$ & $0.98^{\star \star}$ & $0.91^{*}$ \\
\hline PI3K-RNAi & $0.90^{*}$ & $0.84^{*}$ & $-0.85^{\star}$ & $-0.87^{\star}$ & $0.85^{\star}$ & $0.92^{*}$ & $0.88^{*}$ \\
\hline mTOR-RNAi & $0.93^{* *}$ & $0.85^{*}$ & $-0.83^{*}$ & $-0.91^{*}$ & $0.92^{* *}$ & $0.98^{* *}$ & $0.90^{*}$ \\
\hline \multicolumn{8}{|l|}{ Phagocytosis (\%) } \\
\hline Blank & $0.95^{\star *}$ & $0.93^{\star *}$ & $-0.89^{*}$ & $-0.97^{\star \star}$ & $0.95^{\star *}$ & $0.96^{\star \star}$ & $0.97^{\star *}$ \\
\hline Negative control & $0.94^{* *}$ & $0.82^{*}$ & $-0.96^{* *}$ & $-0.94^{* *}$ & $0.99^{* *}$ & $0.90^{*}$ & $0.97^{* *}$ \\
\hline PI3K-RNAi & $0.99^{* *}$ & $0.90^{*}$ & $-0.88^{*}$ & $-0.92^{*}$ & $0.96^{\star *}$ & $0.97^{\star \star}$ & $0.90^{*}$ \\
\hline mTOR-RNAi & $0.99^{* *}$ & $0.82^{*}$ & $-0.87^{*}$ & $-0.98^{* *}$ & $0.94^{* *}$ & $0.92^{\star *}$ & $0.90^{\star *}$ \\
\hline
\end{tabular}

${ }^{*} \mathrm{P}<0.05,{ }^{* *} \mathrm{P}<0.01$ (Pearson's linear correlation analysis).

macrophages. RNAi involves the introduction of exogenous double-stranded RNA into cells to induce the degradation of its corresponding homologous mRNA, thereby post-transcriptionally silencing its target gene (17). RNAi has rapidly become a standard biological procedure as siRNAs yield greater efficiencies than conventional antisense oligonucleotides and ribozymes, and RNAi-mediated knockdown of target genes is relatively feasible compared to gene knockouts via homologous recombination (18). In this study, we successfully silenced the target genes by transfecting shRNA recombinant lentiviral vectors into cells with gene-silencing efficiencies $>80 \%$. The attempt made by Jacinto et al. (19) to silence the expression of mTOR using siRNA led to the upregulation of RhoA. Gan et al. (20) found that Type I PI3K could directly activate mTORC2, and the inhibition of Type I PI3K using LY294002 led to the downregulation of mTORC2 and RhoA. In this study, we found that the expressions of mTOR, RhoA, and p-RhoA were downregulated following the silencing of PI3K, possibly because Type I PI3K, whose expression was silenced in this study, can directly activate mTORC2. Both PI3K and mTOR are located upstream to RhoA, and thus may exert varying effects on RhoA. It has also been found that PI3K could directly activate RhoA $(19,21)$. Moreover, Jeruschke et al. (22) found that the inhibition of mTOR using the immunosuppressant everolimus could partially restore the activity of RhoA, which is consistent with this study that the expressions of RhoA and $p-R h o A$ were upregulated after silencing the expression of mTOR.

Our correlation analysis showed that $\mathrm{PI} 3 \mathrm{~K}$ was positively correlated with RhoA, whereas mTOR was negatively correlated with RhoA. PI3K positively regulates RhoA and is positively correlated with the phagocytic capacity of macrophages, whereas mTOR negatively regulates RhoA and is negatively correlated with the phagocytic capacity of macrophages. Therefore, the downregulation of RhoA and RhoA phosphorylation after silencing the expression of $\mathrm{PI} 3 \mathrm{~K}$ might be attributed to the fact that the positive induction of PI3K on RhoA is greater than the negative effect of mTOR on RhoA, which is consistent with the findings reported in previous studies $(19,23)$, but is different from others (24). The reason could be that mTOR exists in two complexes referred to as mTOR complex 1 and 2 (mTORC1 and mTORC2, respectively), which play different roles in different signaling pathway (25). mTORC1 phosphorylates proteins such as eukaryotic initiation factor $4 \mathrm{E}$ binding protein 1 (4E-BP1), the $70-\mathrm{kDa}$ ribosomal protein S6 kinase 1 (p70S6K1), and uncoordinated-51-like kinase 1 (ULK1), whereas mTORC2 phosphorylates proteins such as Akt $(26,27)$. The repressive effect of RhoA - GTP occurs through a decrease in the amount of Rheb (Ras-homolog enriched in brain) . GTP available to stimulate mTORC1 through RhoA.GTP-mediated repression of mTORC2 leading to reduced Akt signaling to TSC2 (28).

Cytoskeleton comprises actin, microfilaments, and intermediate filaments. Actin plays important roles in cell division, movement, and phagocytosis (29). Phagocytosis refers to the process in which after the recognition of exogenous particles by surface receptors on macrophages, the aggregation of actin at the plasma membrane leads to the formation of pseudopod projections that wrap the phagocytosed particle, followed by the closure of phagocytic cups, depolymerization of actin, and formation of phagolysosomes (30). RhoA is a key protein that regulates cytoskeletons, whereby it can activate its downstream effectors Rho-associated protein kinase (ROCK) and mammalian diaphanous ( $\mathrm{mDia}$ ) to promote myosin contraction and actin rearrangement, which are required for the formation of stress fibers (31). During the complement receptor 3 (CR3)-mediated phagocytosis, RhoA promotes the polymerization of actin and microtubules to form 
phagocytic cups that engulf and digest the phagocytosed particle (32). Salinas et al. reported that the actin polymerization in HeLa cells was obstructed exhibiting reduced phagocytic capacity against rickettsia after silencing the RhoA gene. Inhibition of PI3K led to blocking of AKT phosphorylation and attenuated the downregulation of F-actin genes in pulmonary arterial smooth muscle cell (PASMC) (33). Schlam et al. (34) found that the process of phagocytosis in macrophages was interrupted after inhibiting PI3K, whereby the pseudopod projections were blocked by the formation of shallow phagocytic cups and continuous aggregation of actin, which could not be depolymerized. In this study, we showed that following the silencing of PI3K gene, the macrophages displayed a reduced phagocytic capacity with disordered cytoskeleton arrangements, short pseudopod projections, and a reduced number of stress fibers. The cells exhibited a more pronounced cellular deformation after silencing the mTOR gene with an increased number of stress fibers and enhanced phagocytic capacity. The results showed that the inhibiting of PI3K could inactivate the Akt-RhoA GTPase-actin rearrangement cascade, but the inhibiting of mTOR could upregulate phosphorylation of RhoA.

In summary, both PI3K and mTOR genes were successfully silenced in this study via lentiviral transfection method. We showed that PI3K/mTOR/RhoA signaling pathway affected the phagocytic capacity of macrophages by modulating the cytoskeletal changes. PI3K enhanced the phagocytic capacity of macrophages by positively

\section{References}

1. Vogelmeier CF, Criner GJ, Martinez FJ, Anzueto A, Barnes PJ, Bourbeau J, et al. Global strategy for the diagnosis, management, and prevention of chronic obstructive lung disease 2017 report. Gold executive summary. Am J Respir Crit Care Med 2017; 195: 557-582, doi: 10.1164/rccm. 201701-0218PP.

2. Murray CJ, Lopez AD. Alternative projections of mortality and disability by cause 1990-2020: global burden of disease study. Lancet 1997; 349: 1498-1504, doi: 10.1016/S01406736(96)07492-2.

3. Agusti A, Sobradillo P, Celli B. Addressing the complexity of chronic obstructive pulmonary disease: from phenotypes and biomarkers to scale-free networks, systems biology, and P4 medicine. Am J Respir Crit Care Med 2011; 183: 1129-1137, doi: 10.1164/rccm.201009-1414PP.

4. Xia Q, Hu ST, Zeng XL, Bao HR, Liu XJ. Mechanisms of cytoskeleton and $\mathrm{PI} 3 \mathrm{~K} \delta$-RhoA in fine particulate matter deteriorating phagocytosis defect of alveolar macrophage in mice with chronic obstructive pulmonary disease [in Chinese]. Zhonghua Yi Xue Za Zhi 2017; 97: 18931389, doi: 10.3760/cma.j.issn.0376-2491.2017.24.011.

5. Berenson CS, Kruzel RL, Eberhardt E, Sethi S. Phagocytic dysfunction of human alveolar macrophages and severity of chronic obstructive pulmonary disease. J Infect Dis 2013; 208: 2036-2045, doi: 10.1093/infdis/jit400. regulating phosphorylation levels of RhoA and promoting a proper cytoskeletal rearrangement. On the other hand, mTOR attenuated the phagocytic capacity of macrophages by negatively regulating phosphorylation levels of RhoA and blocking a proper cytoskeletal rearrangement. Therefore, this study highlighted the possibility of developing a specific inhibitor against mTOR to improve the phagocytic capacity of macrophages and reduce the frequency of acute exacerbations in patients with COPD. Moreover, the complex and heterogenic enzymatic pathway of mTOR and the use of mTOR inhibitors for COPD therapy need a more in-depth knowledge of mTOR signaling (35).

In this study, we only silenced the expressions of PI3K and mTOR by RNAi, but did not silence RhoA. The mechanism of the interaction between RhoA and mTOR is not clear. Because we did not determine Akt and F-actin, the mechanism of $A M$ and cytoskeletal rearrangement for $\mathrm{PI} 3 \mathrm{~K} / \mathrm{mTOR} / \mathrm{RhoA}$ pathway is unclear after the expressions of PI3K and mTOR were silenced, and their effect on interaction of mTORC1 and mTORC2 with RhoA is unclear in COPD. Therefore, further research is needed, and should include animal models.

\section{Acknowledgments}

This work was supported by Fund Program: National Natural Science Foundation of China (81670033), and Key Research and Development Programs of Gansu Province (17YF1FA129).

6. Joshi N, Walter JM, Misharin AV. Alveolar Macrophages. Cell Immunol 2018; 330: 86-90, doi: 10.1016/j.cellimm. 2018.01.005.

7. Baranov MV, Revelo NH, Dingjan I, Maraspini R, Ter Beest $M$, Honigmann A, et al. SWAP70 organizes the actin cytoskeleton and is essential for phagocytosis. Cell Rep 2016; 17: 1518-1531, doi: 10.1016/j.celrep.2016.10.021.

8. Levin R, Grinstein S, Schlam D. Phosphoinositides in phagocytosis and macropinocytosis. Biochim Biophys Acta 2015; 1851: 805-823, doi: 10.1016/j.bbalip.2014.09.005.

9. Jean S, Kiger AA. Classes of phosphoinositide 3-kinases at a glance. J Cell Sci 2014; 127: 923-928, doi: 10.1242/jcs. 093773.

10. Xiang S, Li M, Xie X, Xie Z, Zhou Q, Tian Y, et al. Rapamycin inhibits epithelial-to-mesenchymal transition of peritoneal mesothelium cells through regulation of Rho GTPases. FEBS J 2016; 283: 2309-2325, doi: 10.1111/febs.13740.

11. Jhanwar-Uniyal M, Amin AG, Cooper JB, Das K, Schmidt $\mathrm{MH}$, Murali R. Discrete signaling mechanisms of mTORC1 and mTORC2: Connected yet apart in cellular and molecular aspects. Adv Biol Regul 2017; 64: 39-48, doi: 10.1016/ j.jbior.2016.12.001.

12. Freeman SA, Grinstein S. Phagocytosis: receptors, signal integration, and the cytoskeleton. Immunol Rev 2014; 262: 193-215, doi: 10.1111/imr.12212. 
13. Blajecka K, Marinov M, Leitner L, Uth K, Posern G, Arcaro A. Phosphoinositide 3-kinase $\mathrm{C} 2$ beta regulates RhoA and the actin cytoskeleton through an interaction with Dbl. PLoS One 2012; 7: e44945, doi: 10.1371/journal.pone.0044945.

14. Nakayama $\mathrm{H}$, Bruneau $\mathrm{S}$, Kochupurakkal $\mathrm{N}$, Coma $\mathrm{S}$, Briscoe DM, Klagsbrun M. Regulation of mTOR signaling by semaphorin 3F-neuropilin 2 interactions in vitro and in vivo. Sci Rep 2015; 5: 11789, doi: 10.1038/srep11789.

15. Liu L, Das S, Losert W, Parent CA. mTORC2 regulates neutrophil chemotaxis in a cAMP- and RhoA-dependent fashion. Dev Cell 2010; 19: 845-857, doi: 10.1016/j.devcel. 2010.11.004.

16. Xia $P, X u X Y$. PI3K/Akt/mTOR signaling pathway in cancer stem cells: from basic research to clinical application. $A m \mathrm{~J}$ Cancer Res 2015; 5: 1602-1609.

17. Mack N, Mazzio EA, Bauer D, Flores-Rozas H, Soliman KF. Stable shRNA silencing of lactate Dehydrogenase A (LDHA) in human MDA-MB-231 breast cancer cells fails to alter lactic acid production, glycolytic activity, ATP or survival. Anticancer Res 2017; 37: 1205-1212, doi: 10.21873/ anticanres. 11435.

18. Miyagishi M, Hayashi M, Taira K. Comparison of the suppressive effects of antisense oligonucleotides and siRNAs directed against the same targets in mammalian cells. Antisense Nucleic Acid Drug Dev 2003; 13: 1-7, doi: 10.1089/108729003764097296.

19. Jacinto $E$, Loewith $R$, Schmidt $A$, Lin $S$, Rüegg $M A$, Hall $A$, et al. Mammalian TOR complex 2 controls the actin cytoskeleton and is rapamycin insensitive. Nat Cell Biol 2004; 6: 1122-1128, doi: 10.1038/ncb1183.

20. Gan X, Wang J, Su B, Wu D. Evidence for direct activation of mTORC2 kinase activity by phosphatidylinositol 3,4, 5-trisphosphate. J Biol Chem 2011; 286: 10998-11002, doi: 10.1074/jbc.M110.195016.

21. Graupera M, Guillermet-Guibert J, Foukas LC, Phng LK, Cain RJ, Salpekar A, et al. Angiogenesis selectively requires the p110alpha isoform of PI3K to control endothelial cell migration. Nature 2008; 453: 662-666, doi: 10.1038/nature 06892.

22. Jeruschke S, Buscher AK, Oh J, Saleem MA, Hoyer PF, Weber $S$, et al. Protective effects of the mTOR inhibitor everolimus on cytoskeletal injury in human podocytes are mediated by RhoA signaling. PLoS One 2013; 8: e55980, doi: 10.1371/journal.pone.0055980.

23. Liu L, Wang Y, Yu Q. The PI3K/Akt signaling pathway exerts effects on the implantation of mouse embryos by regulating the expression of RhoA. Int $\mathrm{J} \mathrm{Mol} \mathrm{Med} \mathrm{2014;} \mathrm{33:} \mathrm{1089-}$ 1096, doi: 10.3892/ijmm.2014.1701.

24. Gangoiti P, Arana L, Ouro A, Granado MH, Trueba M, Gómez-Muñoz A. Activation of mTOR and RhoA is a major mechanism by which ceramide 1-phosphate stimulates macrophage proliferation. Cell Signal 2011; 23: 27-34, doi: 10.1016/j.cellsig.2010.08.001.

25. Toschi A, Lee E, Xu L, Garcia A, Gadir N, Foster DA. Regulation of mTORC1 and mTORC2 complex assembly by phosphatidic acid: competition with rapamycin. Mol Cell Biol 2009; 29: 1411-1420, doi: 10.1128/MCB.0078208.

26. Sarbassov DD, Ali SM, Sengupta S, Sheen JH, Hsu PP, Bagley $\mathrm{AF}$, et al. Prolonged rapamycin treatment inhibits mTORC2 assembly and Akt/PKB. Mol Cell 2006; 22:159168, doi: 10.1016/j.molcel.2006.03.029.

27. Kim J, Kundu M, Viollet B, Guan KL. AMPK and mTOR regulate autophagy through direct phosphorylation of Ulk1. Nat Cell Biol 2011; 13: 132-141, doi: 10.1038/ncb2152.

28. Gordon BS, Kazi AA, Coleman CS, Dennis MD, Chau V, Jefferson LS, et al. RhoA modulates signaling through the mechanistic target of rapamycin complex 1 (mTORC1) in mammalian cells. Cell Signal 2014; 26: 461-467, doi: 10.1016/j.cellsig.2013.11.035.

29. Lemieux MG, Janzen D, Hwang R, Roldan J, Jarchum I, Knecht DA. Visualization of the actin cytoskeleton: different F-actin-binding probes tell different stories. Cytoskeleton (Hoboken) 2014; 71: 157-169, doi: 10.1002/cm.21160.

30. Mao Y, Finnemann SC. Regulation of phagocytosis by Rho GTPases. Small GTPases 2015; 6: 89-99, doi: 10.4161/ 21541248.2014.989785.

31. Fan Z, Li C, Qin C, Xie L, Wang X, Gao Z, et al. Role of the $\mathrm{PI} 3 \mathrm{~K} / \mathrm{AKT}$ pathway in modulating cytoskeleton rearrangements and phenotype switching in rat pulmonary arterial vascular smooth muscle cells. DNA Cell Biol 2014; 33: 12-19, doi: 10.1089/dna.2013.2022.

32. Yang L, Dai F, Tang L, Le Y, Yao W. Macrophage differentiation induced by PMA is mediated by activation of RhoA/ROCK signaling. J Toxicol Sci 2017; 42: 763-771, doi: $10.2131 /$ jts. 42.763 .

33. Salinas RP, Ortiz Flores RM, Distel JS, Aguilera MO, Colombo MI, Berón W. Coxiella burnetii Phagocytosis IsRegulated by GTPases of the Rho family and the RhoA effectors mDia1 and ROCK. PLoS One 2015; 10: e0145211, doi: 10.1371/journal.pone.0145211.

34. Schlam D, Bagshaw RD, Freeman SA, Collins RF, Pawson T, Fairn GD, et al. Phosphoinositide 3-kinase enablesphagocytosis of large particles by terminating actin assembly throughRac/Cdc42 GTPase-activating proteins. Nat Commun 2015; 6: 8623, doi: 10.1038/ncomms9623.

35. Pasini E, Flati V, Comini L, Olivares A, Bertella E, Corsetti G, et al. Mammalian target of rapamycin: is it relevant to COPD pathogenesis or treatment? COPD 2019; 16: 89-92, doi: 10.1080/15412555.2019.1583726. 